\title{
ACCESS AND WEB-SHARING OF 3D DIGITAL DOCUMENTATION OF ENVIRONMENTAL AND ARCHITECTURAL HERITAGE
}

\author{
C. Tommasi ${ }^{1}$, F. Fiorillo ${ }^{1}$, B. Jiménez Fernández-Palacios ${ }^{2}$, C. Achille ${ }^{1}$ \\ ${ }^{1}$ Department of Architecture, Built environment, and Construction engineering (ABC), Politecnico di Milano, Milano, Italy, \\ (cinzia.tommasi, fausta.fiorillo, cristiana.achille)@polimi.it \\ ${ }^{2}$ Department of Cartographic and Terrain Engineering, Polytechnic School of Avila, University of Salamanca, Avila, Spain., \\ belenjfp@gmail.com
}

\section{Commission II}

KEY WORDS: Cultural Heritage, 3D documentation, 3D surveying, HBIM, Valorisation

\begin{abstract}
:
The techniques and methods to capture and represent in a three-dimensional digital space the shape of objects belonging to Cultural Heritage have become more widespread, regarding both the economic and practical accessibility of technologies and equipment. At the same time, systems and tools have developed to integrate different 3D survey techniques that allow to achievement a complete acquisition of the tangible assets, considering the purposes of the survey, the required accuracy and the representation scale.

The product of an integrated (image-based and range-base acquisition) and multi-scale (architectural and landscape scale) digital survey is a metric 3D reconstruction, potentially suitable for a broader 'use' and 'user' and not only for visualisation and documentation. According to this vision, the 3D model becomes a container of information, which include different type of data depending on the users and the aim of the work. The final result of this process can be the valorisation of the Cultural Heritage and its environment, through the access from experts and non-experts users. The aim of the article is showing the entire pipeline for 3D measurement, survey data acquisition, modelling, and representation of tangible assets and the related layers of information, as "best practice" to improve the Cultural Heritage knowledge, fruition, and sharing.
\end{abstract}

\section{INTRODUCTION}

The 21st century is the Digital or Information Age, based on information technology, increasing the speed and breadth of knowledge turnover within the economy and society, touching all the daily human activities and branches of sciences. In this scenario, also Cultural Heritage is not immune by digital technologies, which changed how people perceive, approach, and use it.

The range of technologies to measure, capture, represent, and share the Cultural Heritage made huge advances, varying regarding costs, scales, purposes and outputs: they become more democratised in terms of both economic and practical accessibility of equipment and techniques, and access to models and information using internet portals (Laing, 2018). The employment of cognitive 3D models that describe the tangible parts of the heritage and contain the related information become mainstream, mostly for planning and monitoring the restoration activities. Within a consideration of Cultural Heritage, however, it is necessary not to lose sight of the need to capture and understand the social aspects of the heritage. It always owns an inner meaning, traditions, stories, and cultural resonance, which constitute the kind of information needed for its fruition and valorisation. The question is: In which way is it possible to combine tangible and intangible aspects inside a digital information system to engage people and produce cultural value?

\subsection{Tangible, intangible, digital, and $\mathrm{CH}$ management 3.0}

The starting point of the article is the definition of Cultural Heritage (CH). The latest and the more useful meaning for the work is the one stated by the European Year of Cultural Heritage 2018 website: "Cultural Heritage has a universal value for us as individuals, communities and societies. It is important to preserve and pass on to future generations. You may think of heritage as being 'from the past' or static, but it evolves through our engagement with it. What is more, our heritage has a significant role to play in building the future of Europe. It comes in many shapes and forms: i) Tangible - for example buildings, monuments, artefacts, clothing, artwork, books, machines, historic towns, archaeological sites. ii) Intangible - practices, representations, expressions, knowledge, skills - and the associated instruments, objects and cultural spaces - that people value. This includes language and oral traditions, performing arts, social practices and traditional craftsmanship. iii) Natural landscapes, flora and fauna. iv) Digital - resources that were created in digital form (for example digital art or animation) or that have been digitalised as a way to preserve them (including text, images, video, and records)".

This definition includes all the topics useful for the process of valorisation:

- $\quad$ Transmission, access, sharing

- $\quad$ Economic relevance

- Community engagement and recognition of values

- Tangible aspects, represented by the physical models and data

- Intangible elements, which regard the experience, stories, traditions that have to be divulgated along with the tangible components

- Digital part, which should be the mean that bonds together tangible and intangible and use the information at disposal to create a valorisation experience

Today the concept of $\mathrm{CH}$ has evolved from a vision where it was considered as an obstacle to economic growth (the model called $\mathrm{CH}$ management 1.0) to a precious resource and a need to bring a sustainable, environmental, social, and economic development (the model called CH management 3.0, Gustafsson 2015, Fig. 1). The movement is from protection and conservation to pro-action and transmission: the idea of $\mathrm{CH}$ become an interdisciplinary and integrated approach that affects all the economy and sees the historical environments as an infrastructure for sustainable development. The aim of $\mathrm{CH} 3.0$ is to involve and guide citizens through a collaborative governance form (Fanzini et al., 2014; Fanzini, 2017), from the early stages of the project (co-design). In this case, the role of the experts is to make people able and aware of detecting the values and potentialities and realising the change. 


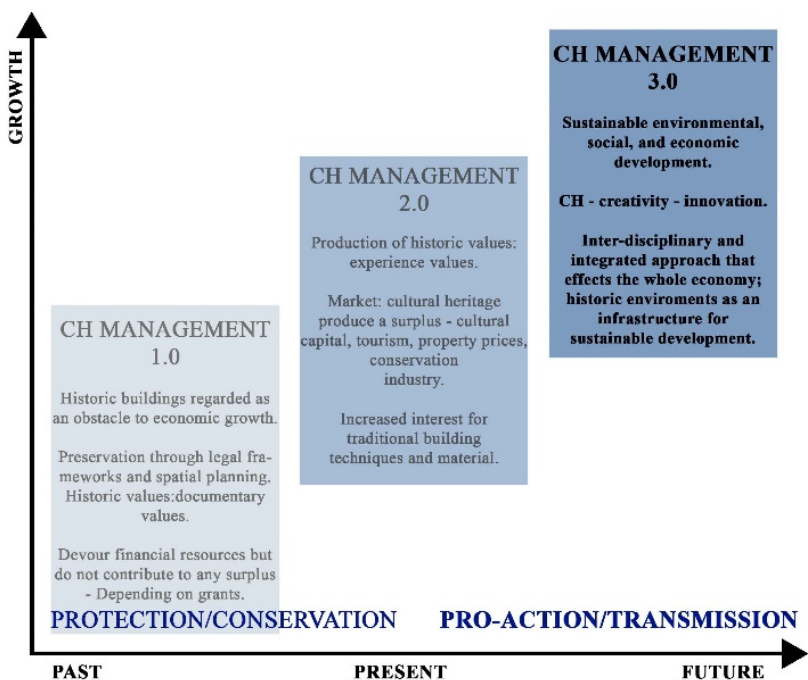

Figure 1: The evolution of Cultural Heritage's management models: the vision passes from protection/conservation to proaction/transmission in CH 3.0 (Gustafsson, 2015).

\subsection{Workflow for valorising Cultural Heritage}

The term valorisation has a broad meaning, according to MiBACT (Ministero dei Beni e delle Attività Culturali e del Turismo): it consists in the activities aimed to promote the knowledge of the national heritage, and to ensure the best conditions of use and access of the heritage to every type of public, to stimulate the culture development. The process to conserve and valorise $\mathrm{CH}$ is multi-disciplinary and requires many theoretical and practical skills, and it could be summarised in three phases.

The first step is the "knowledge phase" that involves two main aspects: i) 3D survey (geometrical and radiometrical acqusitions) and material and decay detection (evaluation of the state of conservation of historical building), that are tangible aspects; ii) historical analysis (intangible elements). This last aspect regards the collection of intangible data that defines a set of values embodied by the studied heritage, like its history, tradition, memories, relationship with the territory and more. The geometrical and radiometrical survey is necessary to define the shape and dimension and colour representation of the historic building and its detailed parts. It represents a fundamental step for any following studies such as the material and decay mapping, the preservation, valorisation and fruition planning. The measurement of the object can be carried out by integrating different 3D survey methods technologies. Therefore this phase is defined with the following pipelines: i) 3D measurement and data acquisition with different approaches; ii) data processing and integration; iii) outputs extraction (e.g. floor plans, vertical sections, elevations, orthoimages, etc.).

Today, the standard outputs along with 2D technical drawings are the 3D digital model (second step "modelling phase"). The reality-based modelling in the $\mathrm{CH}$ field is always not simple, time-consuming and technical skilled. The main reasons are the complex and non-standard shapes of the historical buildings and the high number of different 'semantic' portion and detailed decoration to represent (e.g. colonnade, columns, capitals, cornices, ornaments, etc.). Moreover, above all, modelling from survey data is an interpretation process where it is necessary to choose what the data to represent are and how to describe them, also depending on the detail of the representation scale.

The last step of the process regards the sharing of the data: once the 3D model is built, how is it possible to use it? According to the project's aim (conservation/research or dissemination) and the final user (technical expert or not), the operator selects the information to add to the model and the modalities to share it. The access can happen between experts and another type of users. In particular, the article will show the fruition between different kinds of experts. In any case, the dissemination of the $\mathrm{CH}$ and its content always brought to valorise it and its environment.

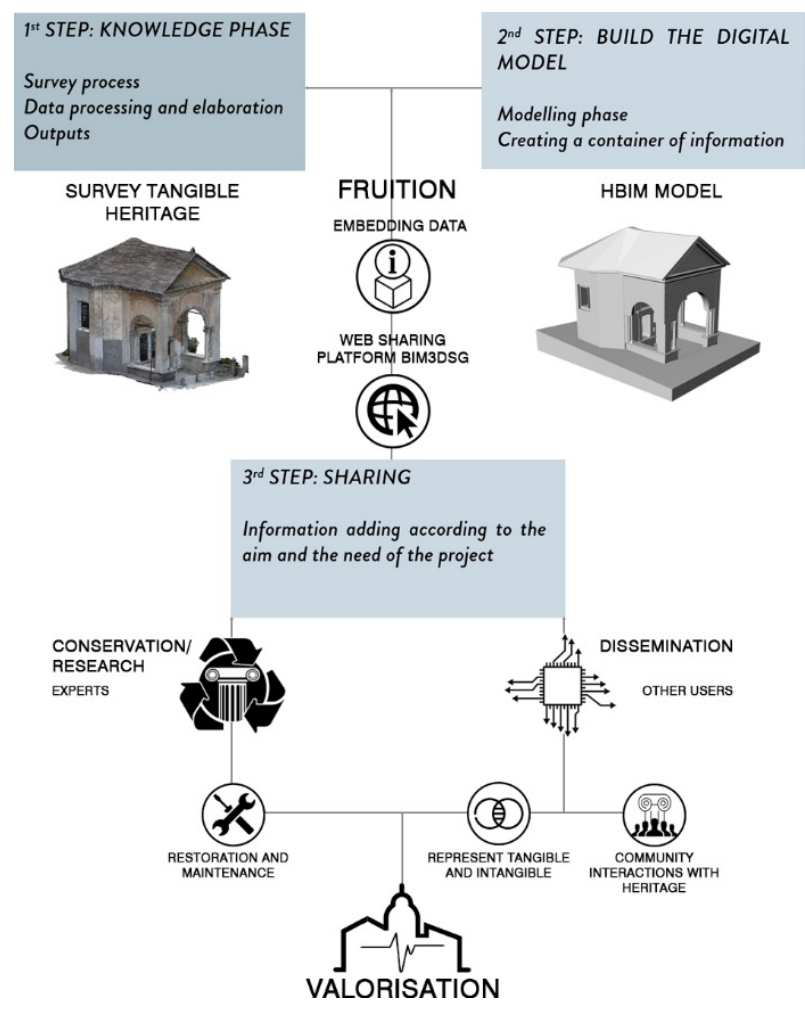

Figure 2: Pipeline from survey data to HBIM modelling, web sharing access and final visualisation.

According to the pipeline presented (Figure 2), the leading research topics developed inside the article are:

- Knowledge phase: experimentation and integration of different systems and technologies of 3D survey for a multi-scale representation (architectural and landscape scale);

- Modelling phase: definition of the workflow from the point cloud to the built of an HBIM model;

- $\quad$ Sharing Phase: methods and modalities for the access and web-sharing of the 3D multi-scale reconstructions and their further information.

\section{APPLICATION FIELD}

The test field choosen to show the application of the workflow and its issues and potentialities is the site of "Sacro Monte Calvario di Domodossola”, Piedmont, Italy. It is a Roman Catholic complex part of the nine "Sacri Monti" of Piedmont and Lombardy, included in the UNESCO World Heritage List from 2003. The complex comprehends a sanctuary and fifteen chapels (containing apparatus of statues and frescoes representing the stations of "via crucis"), built on the top of a hill, place of meditation, nature, art, and architecture since $\mathrm{XVII}^{\circ}$ century (Figure 3). The primary need of the devotional path is the documentation of tangible assets for restoration purposes and ordinary maintenance (expert users), but also the dissemination and the fruition of the place to a broader public (non-expert users). 

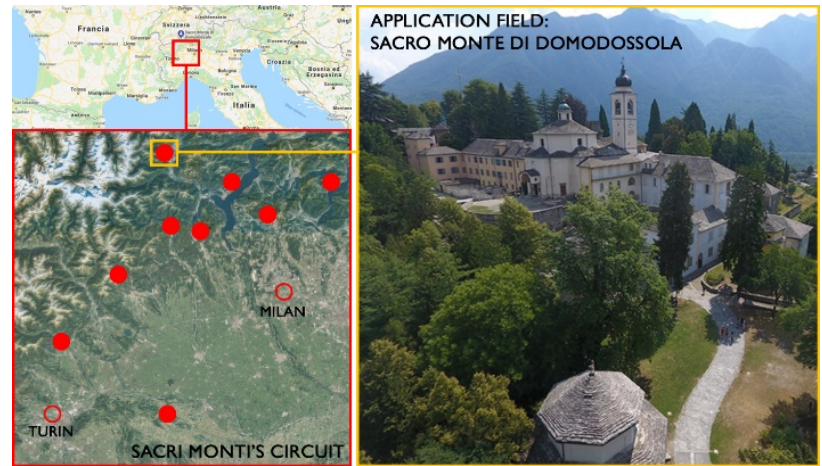

Figure 3: The Sacri Monti Circuit in the North of Italy (on the left), and an aerial view of "Sacro Monte di Domodossola" Sanctuary, which is the application field of the article.

The multi-scale of the site, from the regional map/network to the building, permits to test and integrate different survey techniques to capture both the single chapels (architectural scale), and both the area and environment (landscape scale).

Also, the extraordinary cultural and environmental value let to include in the final outputs of the survey not only the metric/technical restitution and the information required for conservation and maintenance oriented to experts but also the ones that help the better fruition and accessibility-oriented to a broader audience.

The first need of "Sacri Monti" Circuit and objective of the work are to find a method to manage the ordinary maintenance activities of the chapels, which comprehend cleaning, substitution, decay analyses, interventions, and more. In this environment, many people with different competencies, skills, and education have to collaborate, and for this reason, they need a unique platform where to collect their interventions, analyses, and information.

On the other hand, the wish is also to improve the fruition and dissemination of the places, which were a milestone in the history of pilgrims, engaging more people. The workflow to answer these requests is the same presented above, comprehending the knowledge, modelling, and sharing phase (Figure 2).

\subsection{Knowledge Phase: tools used and data acquired}

The first step was the 3D survey of the site integrating different technologies for a multi-scale representation, carried out during the summer school "Laboratory of Places - ISPRS Workshop" organised by the 3D Survey Group - Politecnico di Miano (Achille et al, 2018), in July 2018. During the summer school activities, a complete and accurate 3D survey of six chapels was achieved employing: i) two Terrestrial Laser Scanner (TLS Leica C10 and Leica HDS 7000) for indoor and outdoor measurement; ii) a close-range photogrammetric approach for the outdoor restitutions and iii) a UAV photogrammetric acquisition for the roofs. Moreover, the Leica Pegasus Backpack was used to survey the outdoor scenario of the entire route of the fifteen chapels of the "via crucis".

The Leica Pegasus Backpack (Nocerino et al., 2017) is a wearable Mobile Mapping System useful for the landscape scale representation (Figure 4) and the geo-referencing of 3D measurements. It is equipped with: i) Dual Velodyne VLP-16 scanner sensor for the $3 \mathrm{D}$ coordinates acquisition $(600.000$ $\mathrm{pts} / \mathrm{sec}$ ). The field of view (FOV) horizontal and vertical is $270^{\circ} / 30^{\circ}$ with a range of $50 \mathrm{~m}$; ii) 5 cameras with a $6 \mathrm{~mm}$ focal lens and a coverage of $360^{\circ} \times 200^{\circ}$; iii) includes triple band (LBand, SBAS, and QZSS) to provide georeferenced data by GPS, GLONASS, Galileo, and BeiDou constellations, using single and dual antenna support. The absolute position accuracy outdoor is $5 \mathrm{~cm}$.

The static laser scanner (TLS) and the photogrammetric acquisition were used to satisfy the level of detail of the graphic representations necessary to the architectural scale. The survey was planned to reference to a 1:50 representation scale (plotting error of $1 \mathrm{~cm}$ ). So that in function of these requirements the goal was to obtain an average point-to-point resolution on the object surface of $6 \mathrm{~mm}$ and was set a maximum final Ground Sample Distance (GSD) of about $5 \mathrm{~mm}$ for the photogrammetry dataset acquisition.

A local topographic network was used to reference in the same coordinate system the three different surveys (TLS, terrestrial and aerial close-range photogrammetry) and the local measurements of the six chapels to combine and integrate the final results.

The data processing of the laser scanner survey followed the standard pipeline: 1) "scans alignment” using target; 2) "scans cleaning" to remove noise, outliers, and point affect to edge effect and to leave the best data for each scan station removing longrange data with lower resolution and tangent incident points; 3) "data referencing" using the topographic measurement to rototranslate the final point cloud model in the local coordinate system; 4) "unify and subsample" the final point cloud model to uniform the points density (average resolution of $6 \mathrm{~mm}$ ).

The final point cloud model obtained from the laser scanner survey includes all geometrical information about dimensions and shape (Figure 5), so that was used mainly to extract 2D technical drawing (floor plans and vertical sections, Figure 7).

The standard workflow of the photogrammetric elaboration implied the next steps: 1) "photo-alignment", internal and external calibration; 2) "camera calibration optimization" using the marker detection; 3) "topographic referencing” to scale and reference the 3D reconstruction (in the local coordinate system); 4) "dense cloud creation" and its cleaning; 5) "textured mesh model creation"; 6) "orthoimages extraction" of the main facades and the ceiling (top view) (Figure 8). The topographic measurement was also used to align the terrestrial and the aerial photogrammetric acquisitions to obtain a complete 3D digital model (Figure 6).

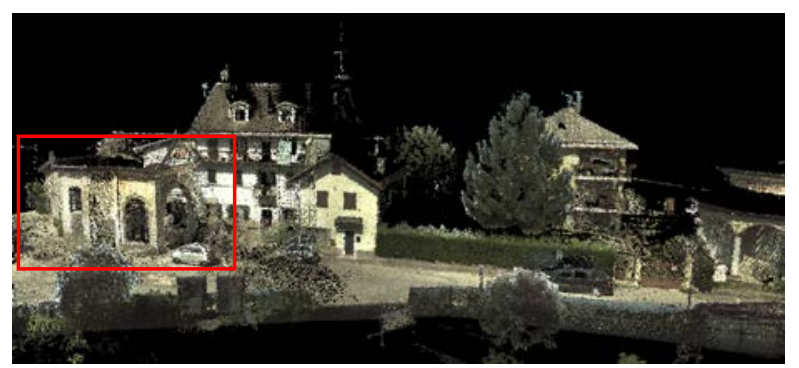

Figure 4: Leica Pegasus Backpack point cloud of Chapel two (landscape scale).

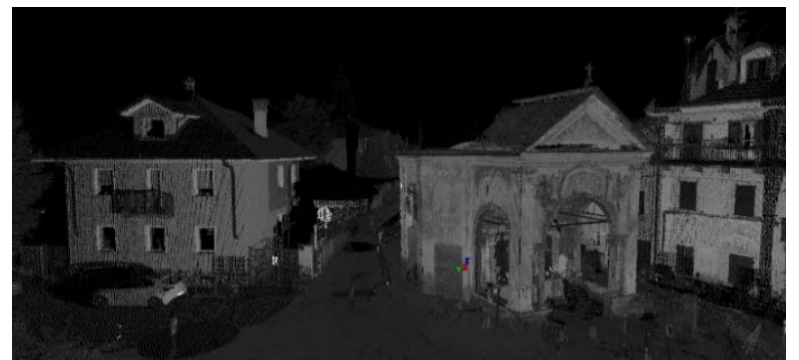

Figure 5: TLS (Leica C10 -10 scan stations) point cloud of Chapel two (architectural scale). 


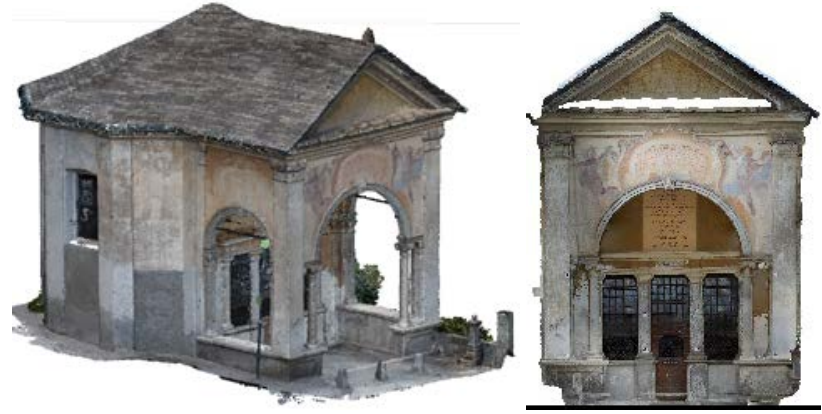

Figure 6: Photogrammetric (terrestrial and UAV - average GSD $3 \mathrm{~m})$ point cloud of Chapel two (architectural scale) on the left, orthoimage of the main façade on the right.
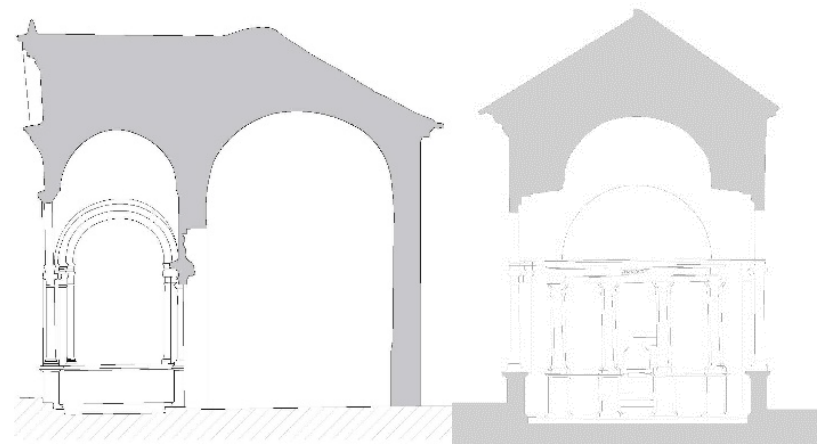

Figure 7: Axial vertical section of the main façade of Chapel two (architectural scale).

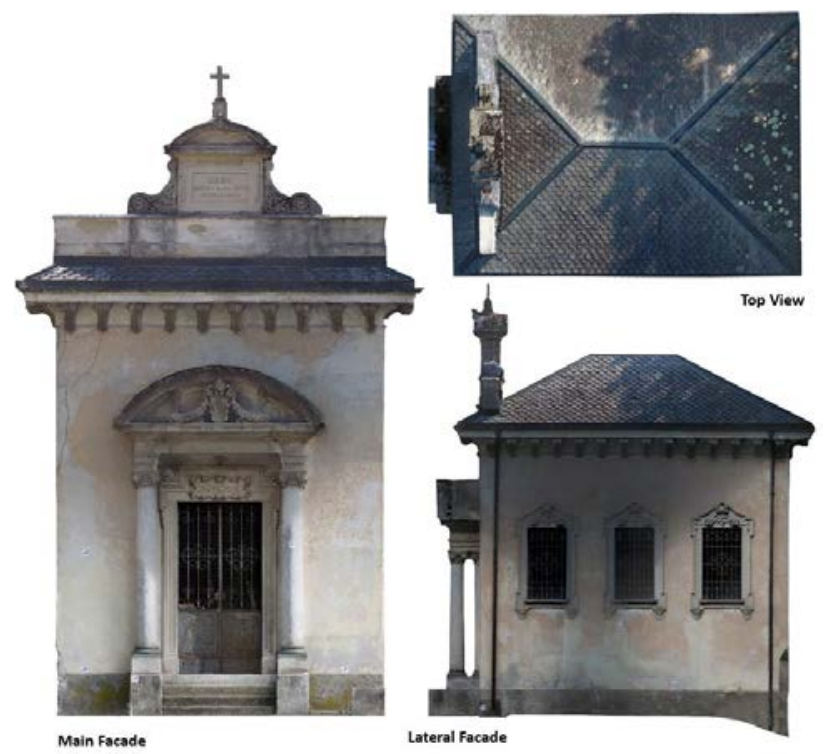

Figure 8: Orthoimages of Chapel three (architectural scale).

The main outputs that can be extracted from the close-range photogrammetric acquisition are detailed (1:50 scale) orthoimages of the main façade and the roofs. On this type of graphic restitution it is possible to develop the material and decay mapping (Figure 9) for the preservations studies, thanks to the image resolution of the final 'metric' orthoimage and the colour information quality (hard to get with standard laser scanner survey).
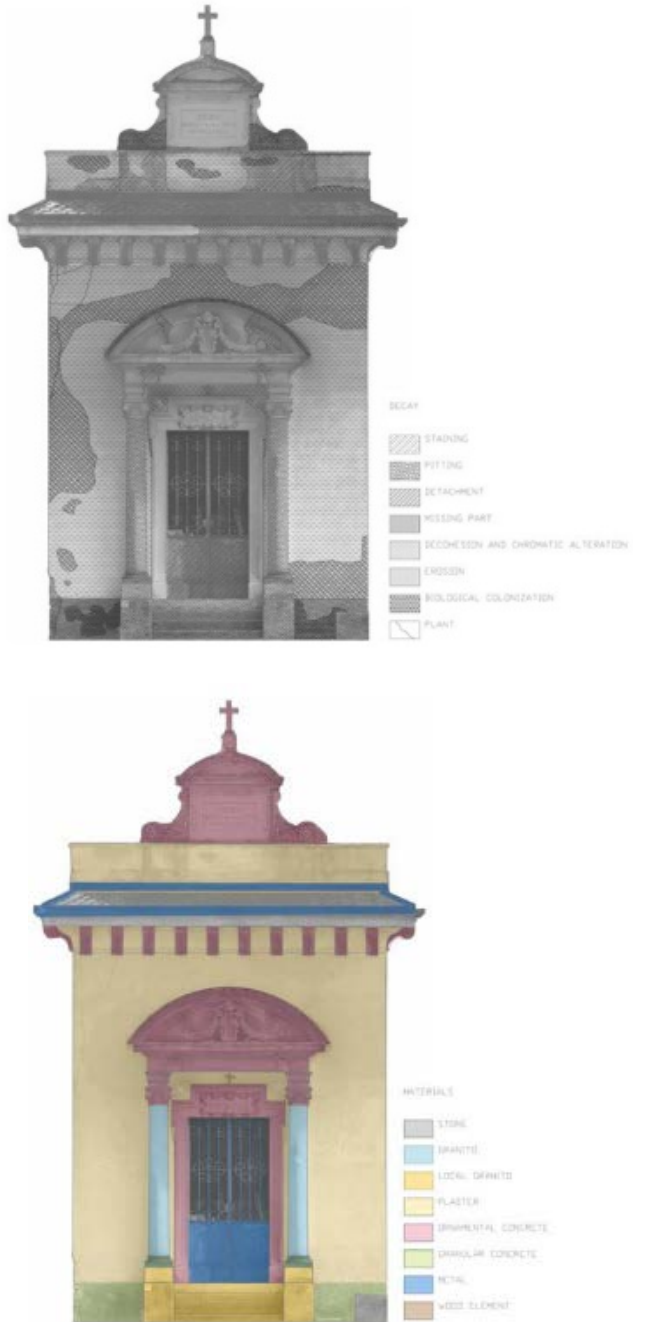

Figure 9: Material and decay mapping of the main façade of Chapel three (architectural scale).

\subsection{Modelling Phase: from point cloud to HBIM}

The employment of information 3D models that describe the tangible parts of the heritage and contain the related data for planning and monitoring the restoration activities become mainstream.

Once the datasets were elaborate, the next step was to transform the rough point cloud into a digital model to enrich them with information: for this reason among different modelling techniques, the choice fell into Building Information Modelling BIM methodology.

The purpose for selecting this technique is the excellent potentialities that it offers connecting the 3D model with an entire information system, and the predisposition of managing the whole life cycle of the building.

Since it spread on the market, the professionals consider BIM as one of the most efficient methods to handle and manage a building and its entire life cycle, including costs, energy simulation, construction and production data, and more. Thanks also to the legislation that came out in the past year, now it is possible to say that this approach is known almost by everyone in the new construction field, and its employment is growing. The National BIM Report 2016 states: "BIM is the future. It is the way the coming generation will work. It will radically change the way we would go about making our rules. Every effort must be made to implement it." 


\section{SIMPLIFICATION OF GEOMETRIES}

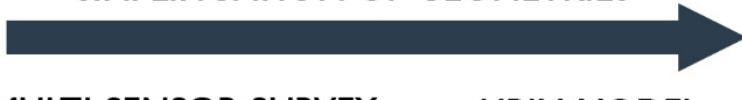

MULTI-SENSOR SURVEY

HBIM MODEL

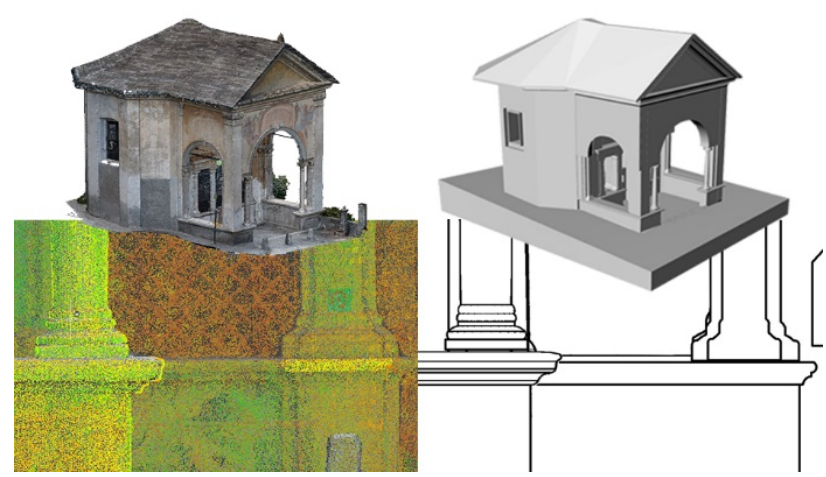

Figure 10: the simplification of HBIM model is an interpretation process from the survey data, which are much higher detailed.

Thanks to the great success of the applications and the possibilities for new buildings, the professionals of the $\mathrm{CH}$ field started to test and experiment in their sector. In particular, the current tendency is to try to manage a large amount of information related to the restoration and ancient world in a BIM software, to help the conservation and valorisation of the building. Today, scientists, professor, researchers, and professionals consider the creation of a mute model of an ancient building as useless. For this reason, also the interdisciplinary experiences and project are spreading, helping a more aware and deepened knowledge of the artefact.

In the case of Sacri Monti's chapels, the starting data was the final point cloud obtained by the integration of photogrammetry (terrestrial and UAV) and laser scanner survey.

This complete and detailed point cloud was imported into Autodesk Revit and then modelled. The restitution had to respect some criteria: i) the division of the digital building model in each of its constitutive element; ii) the fast achievement of a complete result; iii) the simplification of the geometries.

All of these criteria derived by the needs of Sacri Monti. The first requirement can help to use the models for the daily monitoring activities of the chapels. For this reason, it must be possible to visualise and link the information related to the structural, material, decay, and others analyses to every single element of the historical building.

In many cases, for HBIM modelling it would be useless and timeconsuming to try to reach the level of detail of a reality-based 3D reconstruction. The simplification of geometries can help to overcome this difficulty, mainly focusing on the complex shape elements such as decorations, statues, and others, but it is an interpretation process that adds steps to the modelling phase (Figure 10).

In this case, the criterion used for converting the survey's detail into the model's detail was the value of the tolerance. Starting from the 2D profiles, the tolerance helps to establish how to simplify the geometry. Therefore, the 3D model obtained will have a final resolution equal to the tolerance.

Another issue of the modelling phase regards the division of the $3 \mathrm{D}$ model in all the elements required from the conservation needs: it is essential to think carefully about the number of pieces to model and the categories of the objects because what matters next is the massive quantity of information to relate to them.

In this way, the level of detail of the model becomes the high number of the elements and the information contained, instead of the high-definition (number of points or polygons) of the unique shapes. Once the model is built, it is ready to "container" the information although it is not the end of the process. The HBIM model was already divided into pieces according to the needs of the restorers; the next phase is to understand how to display the multi-sensor survey data and the model together, and what kind of information has to match the objects.

\section{SHARING AND ACCESS OF 3D MODELS}

The right to $\mathrm{CH}$ (claim recognised by the Universal Declaration of Human Rights) expresses the possibility to participate to cultural life and contribute to its growth and develops the cultural awareness, mandatory for preserving the authenticity and the memory of a territory. How is it possible to make survey data available and their digital outputs for valorisation purposes and not only for experts? What kind of information is necessary for lifelong activities? What type for valorisation and fruition? It is possible to use the same platform or it is required to personalise it according to the use?

It is possible to say that the three main typologies of fruition of $\mathrm{CH}$ are:

- fruition aimed to the maintenance and restoration activities;

- fruition intended to the public, especially regarding the valorisation of the object from real to virtual, e.g. virtual museums, ad hoc platforms, and more;

- fruition targeted a marketing strategy, taking advantage of the local heritage to create new products.

In all cases of these typologies, the target is always a participated fruition, where people are involved from the early stages of design or processes (bottom-up approach), and they can understand what they are looking. The understanding and the awareness of cultural values helps the development and the growth of a monument, city, or territory.

The languages used in the valorisation projects belongs to the new technologies (virtual, digital, multi-media) and their products are emotional experiences, creates to surprise the public in a vision of "edutainment" (education plus entertainment) (Spallazzo et al., 2009). "Digital experiences are transforming how audiences engage with culture and are driving new forms of cultural participation and practice. As technology advances, so do the behaviours of audiences, especially younger audiences. We are no longer passive receivers of culture; increasingly we expect instant access to all forms of digital content, to interact and give rapid feedback (UK Department for Digital, Culture, Media \& Sport, 2018)”.

Usually, these are the uses of digital (Osservatorio Innovazione Digitale nei Beni e Attività Culturali, 2018):

- $\quad$ services: online ticketing and management;

- communication: websites, social network, app, and more;

- monitoring: individual experience personalised content, feedbacks;

- 3D Models: planned conservation (BIM, online platforms, cataloguing, and more), live experiences (multi-media installations, VR Virtual Reality, AR Augmented Reality), gamification (edutainment), communication (multi-media products), prototyping and printing.

Considering the high number of fields involved, it becomes mandatory the collaboration with other disciplines and specialities. 

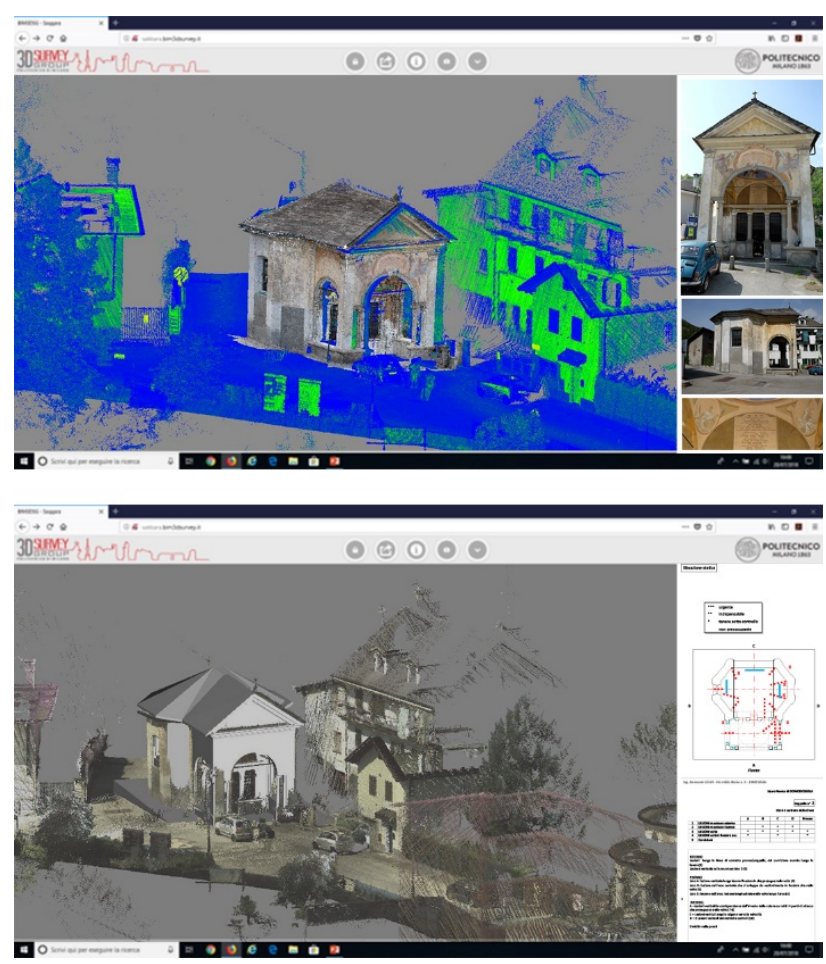

Figure 11: The survey data and 3D models of Chapel two together inside a web-browser and the specific information agreed with the technical office of Ente di Gestione dei Sacri Monti.

The integrated and suitable planning and management of heritage should be based on the mediation amongst institutions, businesses and universities, as well as the other cross-sectional elements connecting these three main protagonists of the valorisation project (Mussinelli, 2014):

- conservation, concerning the growth and the diffusion of knowledge on heritage, its features and particularities and terms of the promotion of new strategies and supply chains aimed at restoration and valorisation;

- $\quad$ usage, as a lever of social and economic sustainability of conservation and precondition for the effective reappropriation of cultural, environmental and landscape heritage;

- development, through promoting creative activities and innovation process relying on heritage to create new values and new heritage (an increase of cultural capital, development of cultural tourism, enhancement of real estate values, entrepreneurial development in the areas of conservation and craftsmanship, etc.).

One of the methods to answer the need for a "common ground" for people with different expertise and skills is the use of an online web-system. The objective of the work was also to enhance the process and use the survey data and their outputs, together in a unique platform, to visualise and analyse at the same time different type of digital products and made the data intelligible to every level of the user.

For this reason, all the data collected were imported in BIM3DSG (Fassi et al., 2012): an online and ad-hoc platform, capable of containing a georeferencing point cloud, polygonal models, orthoimages, photos, textual information, and technical documentation.

The advantages to using a web platform are:

- loading, visualisation, and use of the models in a web browser selecting the level of detail
- $\quad$ updating in real time the progress

- monitoring the conservation of $\mathrm{CH}$

- planning the interventions of restoration and preservation

- management of the information system

- $\quad$ using of mobility and portable devices

- $\quad$ easy-use, no particular skills required

- communication and a better understanding of different professional figures.

The benefit of BIM3DSG system is the possibility to shape it according to the need of the case study. The interface and the functionalities are not the results of the elaboration of a single user, but it is a group work where it is necessary to involve not only the developers but also the final customers (in this case, the technical office of Ente di Gestione dei Sacri Monti). Thanks to the teamwork, the result is accurate and fitted on the real needs of the chapels. In Figure 11, it is possible to see the data coming from survey together with the 3D models, which will be enriched of specific information about the conservation interventions and the state of health of the objects.

For example, speaking about the Chapel two of Sacro Monte di Domodossola "via crucis", the data imported in the web system are:

- $\quad 3 D$ survey data: general point cloud of the site coming from Leica Pegasus Backpack, point cloud of the Chapel two coming from Leica C10 TLS, photogrammetric point cloud of the Chapel two obtained from the integration of UAV and terrestrial photogrammetry. The clouds are geo-referenced using the Leica Pegasus Backpack data like reference.

- Modelling data: the BIM model of Chapel two, georeferenced as the point clouds, and divided in all the elements and categories required from the restorers and workers of Enti Gestione Sacri Monti.

- Conservation information: structural and humidity analyses, decay, 2D drawings, photos, and more.

\section{CONCLUSIONS}

The workflow proposed wanted to highlight the complexity and the potentiality of managing a $\mathrm{CH}$ inside a complete valorisation process, from the survey on the field to the dissemination and fruition. The structured methodology integrates a multi-scale survey data and 3D models inside a digital information system for i) conservation and maintenance purposes; ii) promoting the knowledge of $\mathrm{CH}$ and ensuring the best conditions of use and access of the heritage to every public, stimulating the production of cultural values and development.

The final products do not end in themselves but are part of a more significant process that comprehends conservation/ restoration/ dissemination/ fruition activities, development of communication networks, web-share and remote fruition of tangible and intangible heritage for professional and ordinary users.

The task was to satisfy the primary need of the case study: find a "common ground" for the restorers, specialists, workers, and others that are employed on the ordinary maintenance of Sacri Monti. The solution proposed to help the communication and interoperability between different professionals is an online websystem that permits to view and manage the multi-scale survey data, 3D models, and information of the chapels.

All the three steps of the pipeline require different skills and competencies, issues to overcome, and research lines to follow. Considering the workflow presented in the article, the Table 1 summarises the main issues faced during the three phases, and the main research lines to develop in the future. 
For example, one of the main problem when building the BIM model is to understand what and how many information can enrich it and how these can be used not only from experts. The BIM products/systems are multi-layered by their nature. Consequently, it is essential to classify the different information according to the purpose of the work: is it conservation and maintenance or also dissemination to a broader public?

Speaking about "every kind of user", within a consideration of valorisation projects oriented to $\mathrm{CH}$, it is necessary not to lose sight of the need to capture and understand the intangible aspects of the heritage: traditions, stories, and cultural resonance, values, memory, which constitute the kind of information needed for its access and valorisation.

\begin{tabular}{|c|c|c|}
\hline \multicolumn{3}{|c|}{ WORKFLOW FOLLOWED } \\
\hline PHASE & ISSUES & $\begin{array}{l}\text { RESEARCH } \\
\text { LINES }\end{array}$ \\
\hline $1^{\circ}$ Knowledge & $\begin{array}{l}\text { Technical skills } \\
\text { required for planning, } \\
\text { making and } \\
\text { elaborating a } \\
\text { complete survey } \\
\text { Dealing with a multi- } \\
\text { scale and multi-sensor } \\
\text { survey } \\
\begin{array}{l}\text { Georeferencing all } \\
\text { data }\end{array}\end{array}$ & $\begin{array}{l}\text { Integration of } \\
\text { different sensors } \\
\text { Test the accuracy } \\
\text { and the } \\
\text { potentiality of } \\
\text { new instruments, } \\
\text { tools and pipelines }\end{array}$ \\
\hline $2^{\circ}$ Modelling & $\begin{array}{l}\begin{array}{l}\text { Technical skills } \\
\text { required for } \\
\text { modelling }\end{array} \\
\text { Evaluation of the the } \\
\text { discrepancy between } \\
\text { the level of detail of } \\
\text { the survey and the } \\
\text { final model } \\
\text { Interpretation process } \\
\text { required to pass from } \\
\text { the rough data to the } \\
\text { final output } \\
\text { Understanding how } \\
\text { many pieces are } \\
\text { needed and how to } \\
\text { divide the model }\end{array}$ & $\begin{array}{l}\text { Application of } \\
\text { BIM processes to } \\
\text { Cultural Heritage } \\
\text { Accuracy, LOD, } \\
\text { and } \\
\text { standardisation } \\
\text { Interoperability } \\
\text { between software } \\
\text { and users } \\
\text { Uses of 3D model }\end{array}$ \\
\hline $3^{\circ}$ Sharing & $\begin{array}{l}\text { Find a "common } \\
\text { ground" to collect all } \\
\text { the data elaborated, } \\
\text { the models, and the } \\
\text { information required } \\
\text { Communication } \\
\text { between people with } \\
\text { different skills, } \\
\text { cultural background, } \\
\text { education, and more } \\
\text { Understand what } \\
\text { information is } \\
\text { required to enrich the } \\
\text { models }\end{array}$ & 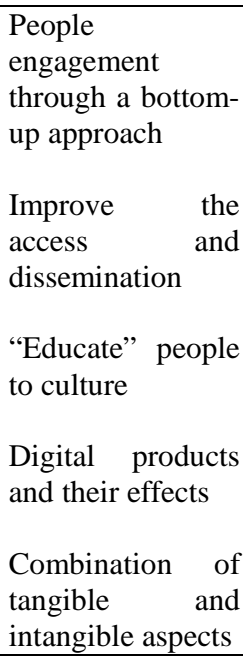 \\
\hline
\end{tabular}

Table 1: Main issues and research lines of the used workflow
The web-system, in this case, could represent a tool where an investigating community can enrich the models bringing its personal experience from the early stages of design (bottom-up approach), and representing a starting point for further developments (Figure 12). In this way, the digital platforms enrich a social, economic, creative, and cultural strategy, becoming a standard to achieve proposing a valorisation project, regardless of where the project is located.

Both the conservation activities combined with the dissemination ones, lead to a complete valorisation, involving professionals, communities, tourists, local people, and others (Figure 13). The process is quite complicated, because of the large number of skills and competencies needed in every step: how the methodologies for conserving and valorising the $\mathrm{CH}$ can be improved?

The role and the experts must guide the community and help to recognise the values of heritage. A good method to support the transmission and the fruition is to organise events, workshops, summer schools, and others, where people are engaged on these topics, developing new expertise.

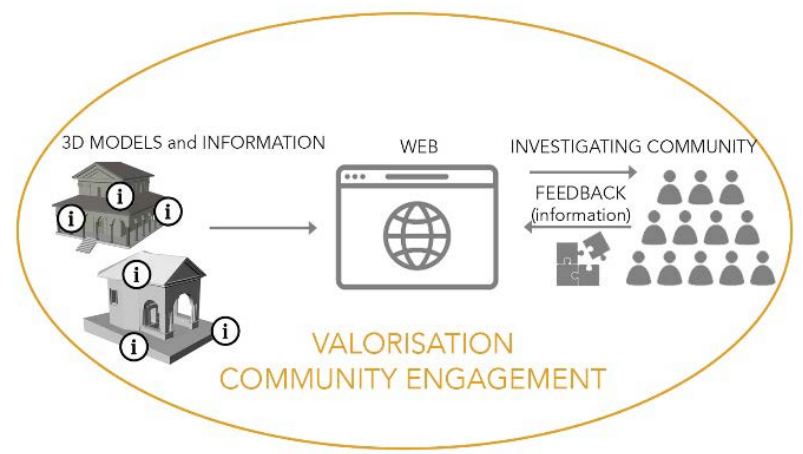

Figure 12: The investigating community can enrich the 3D information model at disposal through the web, adding values, creating knowledge and valorisation, and involving a more significant number of users.

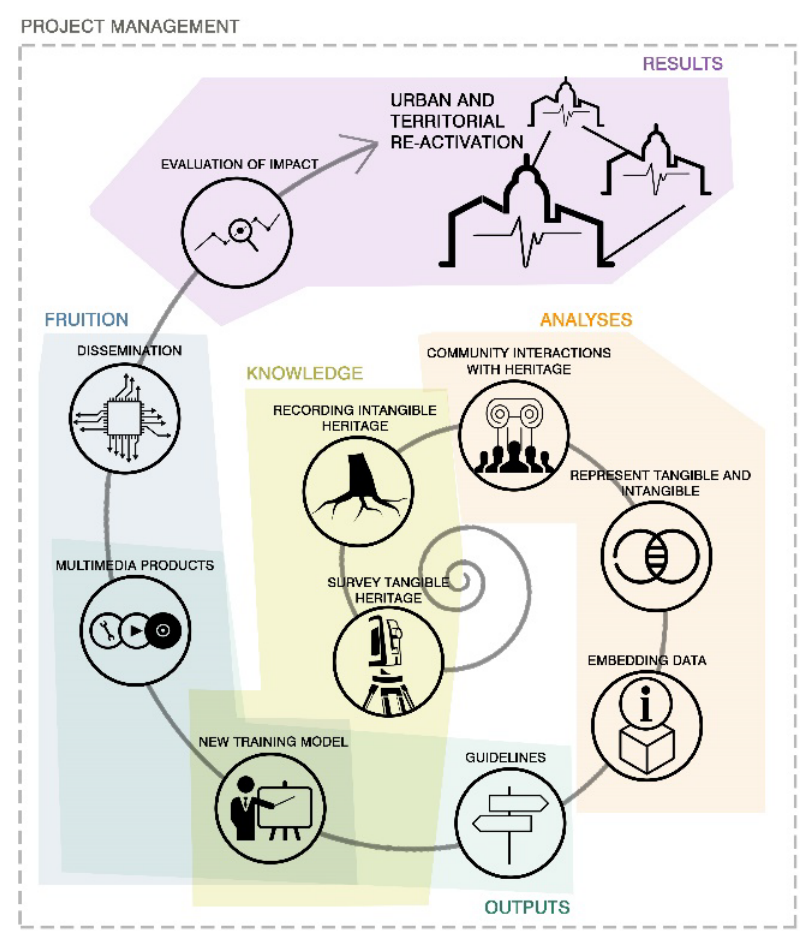

Figure 13: The entire process of valorisation. 
The summer school "Laboratory of Places 2018" organised at Sacro Monte di Domodossola, was a combination of technical skills related to physical parts of the heritage, and a transversal and soft skills related to the intangible elements, such us traditions, surroundings, history, and more.

This experience, which will go on also in 2019, created a network of people and professional, involved local communities, and helped to recognise and appreciate the process of valorisation of $\mathrm{CH}$. Concluding, CH's meaning is enlarging more and more. The theoretical and technical skills are essential to contribute to its valorisation and conservation, which are not anymore only an aim to reach, but also a duty.

It is necessary to invest in research and education to achieve good results and transmit the values. The researchers have to promote joint activities because only encouraging interdisciplinary approaches between professionals and competencies can bring the buildings of the past into the world of the future.

\section{ACKNOWLEDGEMENTS}

The authors would like to acknowledge the other tutors and the students of the "Summer School: Surveying Cultural Heritage Laboratory of Places 2017, Ghesc and Surroundings History, Survey, Evolution" to provide consent to the use of data acquired during the laboratory, the "Ente Di Gestione Sacri Monti" for providing the used technical and historical data, and Padri Rosminiani for their hospitality and patience.

\section{REFERENCES}

Achille, C., Fassi, F, Mandelli, A., and Fiorillo, F., 2018. Surveying Cultural Heritage: Summer School for Conservation Activities. In: Applied Geomatics, Vol. 10(4), pp, 579-592, doi: 10.1007/s12518-018-0225-3.

Achille, C., Lombardini, N., and Tommasi, C., 2018. BIM and Cultural Heritage: Compatibility Tests on Existing Buildings. In: B. Kumar (Ed.), Contemporary Strategies and Approaches in 3D Information Modeling, Hershey, PA: IGI Global, pp. 1-26.

Banfi, F., Chow, L., Reina Ortiz, M., Ouimet, C., Fai, S., 2018. Building Information Modeling for Cultural Heritage: The Management of Generative Process for Complex Historical Buildings. In: Ioannides M. (eds) Digital Cultural Heritage. Lecture Notes in Computer Science, Springer, Cham, Vol. 10605.

Castegnetti, C., Dubbini M., Rivola, R., Giannini, M., Capra, A., 2017. Critical issues and key points from the survey to the creation of the historical building information model: the case of Santo Stefano Basilica. The International Archives of the Photogrammetry, Remote Sensing and Spatial Information Sciences, Vol. XLII-5/W1, pp. 467-474.

European Year of Cultural Heritage 2018, available at: https://europa.eu/cultural-heritage/, (accessed 24 September 2018).

Fanzini, D., 2017. Tecnologie e processi per il progetto del paesaggio. Reti e modelli distrettuali. Maggioli Editore, Santarcangelo di Romagna, IT.

Fanzini, D., Casoni, G., and Bergamini, I. 2014. Valorizzazione dei Beni Culturali \& Sviluppo Locale. Enhancement of cultural heritage and local development. Maggioli Editore, Santarcangelo di Romagna, IT.
Fassi, F., and Parri, S. 2012. Complex Architecture in 3D: from survey to web". International Journal of Heritage in the digital era, Vol. 1, pp 379-398.

Gustafsson, C., 2015. Conservation 3.0 inclusive sustainable an innovative conservation in the Age of Smart Specialisation Strategies, available at: https://campusnackrosen.gu.se/digitalAssets/1556/1556489_gus tafsson-h--gre-seminarium-19-november-2015.pdf, (Last accessed on 04 September 2018).

Kurian, A., and Morin, K. W., 2016. A fast and flexible method for meta-map building for ICP based slam. The International Archives of the Photogrammetry, Remote Sensing \& Spatial Information Sciences, Vol. XLI-B3, pp. 273-278.

Laing, R., 2018. Digital Participation and Collaboration in Architectural Design. Routledge, Oxon, UK.

Leica Geosystems. Leica Pegasus: Backpack Wearable Mobile Mapping Solution. Available at: https://leicageosystems.com/enUS/products/mobilesensorplatforms/captureplatforms/leica-pegasus-backpack (Last accessed on 19 December 2018).

MiBACT, Ministero per i Beni per le Attività Culturali, available at: http://www.beniculturali.it/, (Last accessed on 04 September 2018).

Nocerino, E., Menna, F., Remondino, F., Toschi, I., RodríguezGonzálvez, P., 2017. Investigation of indoor and outdoor performance of two portable mobile mapping systems. In: Videometrics, Range Imaging, and Applications XIV, Vol. 10332.

Rechichi, F., Mandelli, A., Achille, C., and Fassi, F., 2016. Sharing high-resolution models and information on web: The web module of BIM3DSG system, The International Archives of the Photogrammetry, Remote Sensing and Spatial Information Sciences., Vol. XLI-B5, pp. 703-710.

Scianna, A., Gristina, S., and Paliaga, S. 2014. Experimental BIM Applications in Archaeology: A Work-Flow. Proc. Of the 5th Int. Conf. on Digital Heritage. Progress in Cultural Heritage: Documentation, Preservation, and Protection, pp. 490-498.

Spallazzo, D., Spagnoli A., and Trocchianesi, R., 2009. Il museo come organismo sensibile. Tecnologie, linguaggi, fruizione verso una trasformazione design-oriented. Congresso Nazionale AICA, Associazione Italiana Informatica e Calcolo Automatico. 